\title{
Special issue: Petr Štěpánek
}

\author{
Sergey K. Filippov ${ }^{1}$ - Christine M. Papadakis ${ }^{2}$ - Oleg V. Borisov ${ }^{3}$
}

Published online: 8 June 2017

(C) Springer-Verlag GmbH Germany 2017

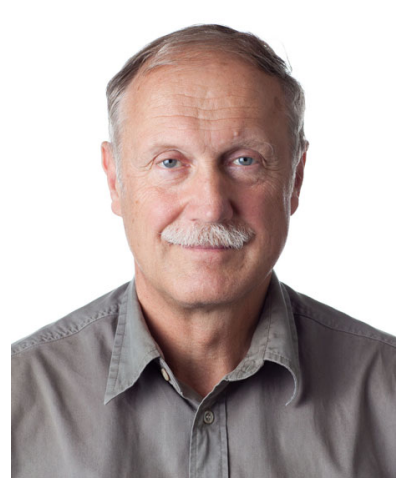

Dr. Petr Štěpánek is celebrating his 65 th birthday this year. To appreciate both his anniversary and his important contribution to contemporary polymer science, Springer is pleased to launch the present special issue of Colloid and Polymer Science dedicated to Dr. Petr Štěpánek. His colleagues,

Sergey K. Filippov

filippov@imc.cas.cz; sfill225@gmail.com

Christine M. Papadakis papadakis@tum.de

$\triangle$ Oleg V. Borisov oleg.borisov@univ-pau.fr

1 Institute of Macromolecular Chemistry, AS CR, Heyrovsky Sq. 2, Prague 6, 16206 Prague, Czech Republic

2 Physik-Department, Fachgebiet Physik weicher Materie, Technische Universität München, James-Franck-Str. 1, 85748 Garching, Germany

3 Institut des Sciences Analytiques et de Physico-Chimie pour l'Environnement et les Matériaux, UMR 5254, CNRS, UPPA, Pau, France coworkers, and former students contribute to this special issue with their own selected original scientific work in order to honor Dr. Petr Štěpánek not only as a prominent scientist but also as a friend and colleague with an outstanding personality.

Petr Štěpánek graduated in 1978 from Charles University in Prague in chemical physics and then obtained in 1981 his $\mathrm{PhD}$ doctoral degree in experimental physics of polymers under the supervision of Prof. Vacek from Charles University and Dr. B. Sedláček from the Institute of Macromolecular Chemistry of the Czech Academy of Sciences. Since that time, his scientific life was closely linked to the Institute of Macromolecular Chemistry. After his PhD defense, Petr Štěpánek went for a post-doctoral stay at the Commissariat à l'Energie Atomique in Saclay, France where he spent 2 years with professors M. Adam and P. G. de Gennes. At that time, he used dynamic light scattering and small-angle neutron scattering to study fundamental properties of polymer solutions, the theory of which was being developed by P. G. de Gennes. After returning to Prague, Petr Štěpánek implemented the acquired knowledge to study self-assembling polymeric systems. During those fruitful years, he developed many new ideas concerning the measurements of dynamic modes in polymer solutions. Special emphasis was drawn on the development of a new experimental setup for dynamic light scattering and numerical methods for calculations of the particle size distribution functions. With this new setup, it became possible to measure DLS spectra in an extremely broad temperature range ( -120 up to $\left.400{ }^{\circ} \mathrm{C}\right)$. His efforts were recognized in 1986 by the award of the Czech Academy of Sciences. Having become an expert in the radiation scattering methods, he used them further to study the critical phenomena in polymer blends and dynamics of block copolymer micelles. He spent twice his sabbaticals in 1989-1990 and 1994 as a visiting scientist at the University of Minnesota in Minneapolis with professor Timothy Lodge. After returning 
to the Institute of Macromolecular Chemistry, he took in 1997 the position of Head of Department of Supramolecular Polymer Systems. Since 2007, he acts as Deputy Director of the Institute.

Petr Štěpánek supervised 15 theses of $\mathrm{PhD}$ students who came to Prague from different countries to work with him. Nowadays, some of his former PhD students hold highranked positions in academia or in industry around the world.

In recognition of his scientific success, Petr Štěpánek was granted in 2001 the doctor of Science degree which is the highest and most prestigious degree in the Czech Academy of Sciences. In 2002, he received the prize of Czech Learned Society for his contributions in the field of structure and dynamics of macromolecular systems.

His current research interests are focused to self-organization phenomena in macromolecular systems, design, and characterization of functional polymeric materials for biomedical applications. His research team performs synthesis and characterization of tailored self-associating polymers for diagnostic and therapeutic applications (including fluorescently and radioactively labeled polymers), biodegradable polymers for drug delivery, block, gradient, and block-gradient copolymers forming complex supramolecular assemblies. Special attention is paid to polymeric systems responsive to external stimuli, in particular to changes in $\mathrm{pH}$, temperature or chemical environment. Petr Štěpánek is a world recognized expert in such advanced experimental techniques used for investigation of polymer systems as scattering of light, X-rays, neutron and synchrotron radiation, and fluorescence correlation spectroscopy. Under his supervision, novel experimental approaches were developed such as simultaneous dynamic light and neutron scattering,
DLS of block copolymers in electrical field, and ultra-small angle DLS. The scientific results obtained by Petr Štěpánek together with his coworkers were published in many highly cited papers and presented at major international conferences. On behalf of his outstanding contributions to polymer physics and chemistry, Petr Štěpánek and his group received the award of the Czech Academy of Sciences (2016).

Petr Štěpánek has built up a strong network of international scientific collaboration across Europe and beyond with collaborators in the U.S., France, China, Germany, Brazil, and many other countries.

It fits into the line of these activities that Petr Štěpánek organized in Prague several Prague Macromolecular Meetings such as Optics and Dynamics in Polymers (1993), Structure and Dynamics of Self-Organized Macromolecular Systems (2006), and Self-assembly in the World of Polymers (2016), and two international conferences like the European Science Foundation EUROCORES meetings BIOSONS (2006), and SONS2 (2010).

Petr Štěpánek is a member of the Editorial Advisory Board in the European Polymer Journal.

The guest editors would like to thank all contributors to this special issue of Colloid and Polymer Science for their constructive and fruitful cooperation. It is only with their help and the quality of their selected research work that this special issue can have such an outstanding quality, appreciating and celebrating Petr Štěpánek’s scientific achievements.

Dear Petr, we and all the contributors would like to wish you to stay always in the best shape and mood and to get, many, many more new splendid ideas and exciting projects. 